Anales de Literatura Hispanoamericana

ISSN-e: 1988-2351

\title{
Capitalismo, historia y autoficción: una propuesta rizomática
}

\section{René Camilo García Rivera ${ }^{1}$}

Resumen. El género autoficcional explota al máximo las tensiones entre realidad, inventio y ficción. Genera un espacio donde se imbrican las vivencias personales, los hechos históricos y escenas inventadas por el autor que ponen en entredicho la distinción entre verdad y mentira, entre lo verdadero y lo falso. A la crítica, frecuentemente, le ha costado lidiar con la ambigüedad propia del género, definido por primera vez en 1977 en un texto de Serge Doubrovsky. El presente artículo parte de las concepciones teóricas predominantes en la crítica autoficticia, pero propone la síntesis con otros postulados adyacentes al problema: la concepción de mundo de Ludwig Wittgenstein, el rizoma de Gilles Deleuze y Félix Guattari, y el "carácter destructivo" identificado por Walter Benjamin. La integración de estas líneas de pensamiento favorecen una comprensión renovada del género autoficcional, que sin negar o abandonar los enunciados teóricos predominantes, ofrece nuevas perspectivas de análisis al problema.

Palabras clave: autoficción; realidad/ficción; capitalismo; historia; rizoma.

\section{[en] Capitalism, history and autofiction: a rhizomatic proposal}

Abstract. The autofiction exploits tensions between reality, inventio and fiction. It generates a space where personal experiences, historical events and scenes invented by the author are interwoven that put into question the distinction between truth and lie, between true and false. Criticism has often struggled to deal with the ambiguity of the genre, defined in 1977 in a text by Serge Doubrovsky. This article adopts the predominant theoretical conceptions about autofiction, but proposes the synthesis with other postulates adjacent to the problem: the worldview of Ludwig Wittgenstein, the rhizome of Gilles Deleuze and Félix Guattari, and the "destructive character" identified by Walter Benjamin. The integration of these lines of thought favor a renewed understanding of the autofictional genre, which without denying or abandoning the predominant theoretical statements, offers new perspectives of analysis to the problemator.

Keywords: autofiction; reality/fiction; capitalism; history; rhizome.

Sumario: 1. Hitos epistémicos en la ficción: Hume, Wittgenstein y el consenso postmoderno. 2. Autoficciones: una propuesta rizomática entre Literatura, Capitalismo e Historia. 3. Conclusiones. Anexo I. Plano base de una explosión ficcional. Anexo II. Máquina ficcional de factura wittgensteiniana.

Cómo citar: García Rivera, R.C. (2021) Capitalismo, historia y autoficción: una propuesta rizomática, en Anales de Literatua Hispanoamericana 50, 415-430.

"Die Welt ist alles, was der Fall ist"2. Ludwig Wittgenstein, Tractatus Logico-Philosophicus

En algún momento del siglo XX, la literatura se cansó de la literatura. Entiéndase: el campo epistémico de la literatura se agobió del arte literario, para desparramarse y reterritorializarse en otros cruces, o para extraviarse en la debacle (estética) y reaparecer en guiones de telerrealidad, post de redes sociales o anuncios

\footnotetext{
${ }^{1}$ Universidad de Concepción. Chile.

E-mail: laletraincomoda@gmail.com

${ }^{2} \mathrm{El}$ mundo es todo lo que acaece.
} 
publicitarios de condones y tampax. Acaso si escribir poesía después de Auschwitz fuera una barbarie ${ }^{3}$, estudiar las belles lettres fuese un anacronismo.

El campo literario de postguerra se escindió en maoístas-estalinistas (que buscaban la plusvalía entre las letras, aunque chocaran de cabeza con los puntos), y los agentes culturales capitalistas (que se embolsaban las ganancias de la creciente Industria Cultural). En medio, además de los entusiastas anti-sistema de siempre (anarquistas postmodernos), un puñado de lúcidos que, sin saberlo, pensaban el mundo posterior al Berlín del $89^{\prime}$.

La Caída del Muro y el colapso soviético parecieron ratificar las tesis de Alexandre Kojève sobre el fin de la historia. Solo las negaban la tozudez de Fidel Castro y la aberración de Kim Jong-il (Deng Xiaoping y Nguyễn Văn Linh, los otros líderes comunistas en el poder, se habían orientado a la economía de mercado hacía años ${ }^{4}$ ), y las monarquías petroleras del Golfo Pérsico. Antes que Francis Fukuyama (1992) vulgarizara el concepto con la perspectiva estrictamente economicista, Kojève retomó el enfoque holístico de Hegel. Asumió la batalla de Jena como el punto culminante de la Historia porque el hecho consolidó el Estado Burgués sobre el Feudal. Al imponerse el sistema napoleónico, que codifica y racionaliza el Derecho Civil ${ }^{5}$, se arriba al final de la Historia -según estos pensadores-, pues se concreta un Contrato Social insuperable. Para Kojève, los sucesos que han ocurrido desde entonces son apenas la expansión del fenómeno al resto del mundo $(2013)^{6}$.

Esta idea es compartida por Georges Bataille, quien en la década de 1930 mantuvo una fluida correspondencia con Kojève. "Admito (como hipótesis verosímil) -afirma Bataille- que la historia ya está acabada (con excepción del epílogo)"7 (Hollier, 1982: 111). Este "epílogo" parece el tránsito entre la sociedad feudal y la implantación global del American way of life, el "género de vida propio del período posthistórico" (Kojève, 2013: 437). En la actualidad apenas quedan rezagos focalizados del mundo feudal, pero la "bonanza" del American way of life está reducido a un puñado de naciones de Europa Occidental y Norteamérica; e incluso, dentro de esas naciones, solo una parte de la población goza del "género de vida propio de la posthistoria". El resto, la mayoría del mundo, se halla en un punto que no explican Hegel ni Kojève, que Marx no previno, y que Fukuyama ignora. Giorgio Agamben (2006) lo define como ultrahistoria:

La supervivencia de la humanidad a su drama histórico parece insinuar que hay -entre la historia y su finuna franja de ultra-historia que recuerda el reino mesiánico de mil años que, tanto en la tradición judía como en la cristiana, se instaurará sobre la tierra entre el último acontecimiento mesiánico y la vida eterna. (27)

La ultra-historia es el tiempo que rige en la Avenida de Mayo, de Buenos Aires, y en las urbanizaciones puertorriqueñas del Bronx; en el Barrio Copto del Cairo, y en los suburbios de Kuala Lumpur, desde donde los vendedores ambulantes observan, en el horizonte, el brillo de las Torres Petronas, y sueñan con ocupar una oficina en el piso 88, lejos del sopor agobiante de la calle y el olor a aceite requemado, pues la ultrahistoria vive el deseo (usualmente ingenuo) de alcanzar el paraíso post-histórico. Así, aunque Nairobi, Tirana y Asunción se asemejen más a la Prusia de Federico Guillermo que a Ginebra, el camino hacia la posthistoria parece claro: el crecimiento y liberación de las fuerzas productivas, la infalibilidad organizadora del mercado.

"[E]l hombre ha alcanzado ya su télos histórico -advierte Agamben- y no queda otra opción [...] que la despolitización de las sociedades humanas a través del despliegue incondicionado de la oikonomía (economía, en griego)" (2006: 140). La globalización neoliberal que siguió al derrumbe soviético, promovida

\footnotetext{
${ }^{3}$ Aseveración de Theodor Adorno en la revista Kulturkritik und Gesellschaft [Crítica cultural y sociedad], en 1951.

${ }^{4}$ Desde que Deng Xiaoping ascendió al poder en la República Popular China, impulsó una serie de reformas económicas orientadas al mercado, que pretendían dejar atrás la etapa maoísta de la Revolución Cultural. Vietnam, por su parte, impulsó a partir de 1986 la llamada Đổi mới ("renovación"), que impulsó la creación de empresas bajo el régimen del libre mercado. En lo económico, ambas políticas se alejaron del marxismo ortodoxo de planificación centralizada que rigió en la Unión Soviética y los demás países del Pacto de Varsovia.

${ }^{5}$ El Estado Napoleónico se construye bajo las normas del Código Civil Francés, aprobado en 1804 y vigente en la actualidad (aunque con importantes reformas). Este corpus legal fue el primero por el que se rigió una sociedad capitalista, y reconoció iguales derechos y deberes a todos los ciudadanos.

${ }^{6}$ Esos acontecimientos están destinados, piensa Kojève, a conseguir la consecución de un Estado Democrático (en el sentido burgués), aunque para ello acaezcan momentos de retroceso (Las Guerras Mundiales, las Dictaduras militares, los regímenes totalitarios, etc).

${ }^{7}$ Misiva firmada el 6 de diciembre de 1937.
} 
por el pensamiento hegemónico de los 90 's, constituye la máxima expresión de esta certeza ${ }^{8}$. Si tras 1789 la Razón desplazó a Dios en el altar, después del Tratado de Versalles el Mercado se ha impuesto a la Razón?. No es que, en cada caso, lo nuevo sustituya a lo viejo, sino que lo superpone, le añade rasgos propios sin extinguir los ajenos: para los franceses era Diosa Razón; para los contemporáneos, Wall Street, la bolsa, la pretensión de racionalizar con ciencia (Economía, Matemática, Finanzas) la naturaleza omnipresente, todopoderosa y omnisciente del Mercado.

El Tratado de Versalles, el resultado de la Primera Guerra Mundial, viene a ser (en la lógica de HegelKojève) el epílogo de la batalla de Jena, la reafirmación de supremacía de un sistema político que sería incuestionable (incluso los países socialistas asumieron los principios de los Códigos Civiles del liberalismo, en lo referido a la igualdad de derechos y en la protección universal de la Ley). "Solo" faltaba que esa "superioridad política" se materializara, para toda la especie, en el bienestar bioeconómico prometido. La aspiración, rotulada en la consigna del American way of life, llegaría de mano del crecimiento económico infinito, la sapiencia del Mercado, la riqueza de la tierra y el trabajo incombustible del humano. La sombra de esta aspiración no solo ha modelado nuestra representación de futuro, sino además $-\mathrm{y}$ es lo que más interesa a este trabajo- la interpretación y reconstrucción del pasado y el presente, la forma cómo se recuerda, se transmite y se narra "lo que acaece".

El zeitgeist ${ }^{10}$ contemporáneo subyace en la tensión entre el deseo post-histórico de la ultra-historia y su incapacidad de conseguirlo, entre el mes que queda al final de sueldo y la evasión opiácea de las tarjetas de crédito (con las inevitables cuotas de Damocles en la cabeza). El zeitgeist necesita tiempo para (re)formarse, representarse y narrarse, pero la medida del tiempo en el liberalismo es el dinero; o sea: el liberalismo (en particular el neoliberalismo) ha construido su zeitgeist en función del dinero, y la tecnología moderna ha propiciado que el dinero (clave en nuestra cosmovisión) resulte cada día más difuso, menos tangible, más imaginario ${ }^{11}$. Vicente Verdú (2003) llama a este rasgo de la ultra-historia "capitalismo de ficción", pues el sistema trabaja -sobre todo- con dinero invisible, magnitudes y bienes virtuales ${ }^{12}$.

El American way of life halla un aliado en el capitalismo de ficción. Más aun: encuentra en el capitalismo de ficción su más verosímil puesta en escena. A su vez, el capitalismo de ficción se identifica y asume como modelo al American way of life, de ahí su conflicto inevitable con la realidad de la ultra-historia, pues el olor a aceite requemado del vendedor ambulante de Kuala Lumpur le recuerda el abismo con el piso 88 de las Torres Petronas: el capitalismo de ficción "trata con la realidad para desprenderla de la peste de lo real" (Verdú, 2003: 33), para moldearla según su frustrada expectativa post-histórica, y para ello no le queda más camino que editarla, que "ficcionalizarla". La ficcionalización del dinero constituye el ejemplo más claro de esta evasión.

Algunos instrumentos financieros contemporáneos vuelven difusas las fronteras de los ingresos; particularmente, el acceso automático a líneas de crédito asociadas a cuentas corrientes. Antes, el salario y los ahorros eran la medida del "dinero propio real" para la mayoría de las personas, pero en la actualidad esa medida se ha distorsionado por el "dinero crediticio automático", que posee una naturaleza ambigua. El "dinero crediticio automático" (que puede sumarse instantáneamente al salario) es "real y propio" en tanto funciona para el usuario como medio de pago de bienes y servicios, pero "ficticio y ajeno" en tanto proviene del capital bancario. Más ficticio en cuanto la transacción suele realizarse con dinero electrónico, que ya es de por sí -como se dijo- una ficcionalización del billete, y el billete una ficcionalización del tiempo de trabajo. El crédito es el perfume con el que el capitalismo de ficción disimula la "peste de la realidad", con el que ofrece a la ultra-historia la ilusión (simulada) de estar un paso más cerca del paraíso post-histórico.

${ }^{8}$ Agamben (2006) describe cómo la aspiración al American way of life ha calado en nuestra naturaleza como especie: “¿No vemos quizás alrededor de nosotros y entre nosotros hombres y pueblos sin esencia y sin identidad [...] buscar en cualquier lugar a tientas, y al precio de groseras falsificaciones, una herencia y una tarea, una herencia como tarea? Hasta la pura y simple deposición de todas las tareas históricas [...] en nombre del triunfo de la economía, asume hoy a menudo un énfasis en que la misma vida natural y su bienestar parecen presentarse como la última tarea histórica de la humanidad [...]" (141).

${ }^{9}$ Si Jena constituyó el Fin de la Historia para Francia, la capitulación alemana de 1918 lo fue para Europa. Con el fin de la Primera Guerra Mundial no solo se derrotó a la Triple Alianza, sino que se impusieron los sistemas liberales (Francia, Gran Bretaña, Estados Unidos), a los imperios monárquicos (Alemania, Austria-Hungría, Otomano). También provocó el fin del reinado zarista en Rusia, aunque ello no implicó, de momento, la imposición del Sistema liberal.

${ }^{10}$ Concepto hegeliano que alude al "espíritu del tiempo", para referirse al clima intelectual, estético, ético y artístico de una época.

${ }^{11}$ ¿Qué es el dinero electrónico sino una abstracción del efectivo, una ficcionalización del billete? ¿Y qué es el billete sino una abstracción de cierta cantidad de tiempo de trabajo?

${ }^{12}$ Las criptomonedas como el Bitcoin, Ethereum y Petro (cuyo valor multiplica las divisas internacionales más poderosa) resultan la máxima expresión de este modelo. 
Esta tendencia al simulacro, junto al "individualismo gregario", constituyen los "dictados de nuestro tiempo" para Manuel Alberca (2007). El teórico español considera al género autoficcional en sintonía con los rasgos epocales, donde "lo real encumbra directamente la jerarquía y la majestad del simulacro" (284); y más aún, como resultado mismo de la circunstancia ultra-histórica: “[...] si la autoficción destaca en esa frontera o cruce que es la línea de intersección entre lo ficticio y lo real [...] es porque ella misma funciona gracias a dicha oposición" (48). Entonces, para llegar a un entendimiento preciso del género, resulta pertinente indagar los campos que, en su oposición, lo delimitan.

\section{Hitos epistémicos en la ficción: Hume, Wittgenstein y el consenso postmoderno}

La ultra-historia es el tiempo de la contaminación paradójica. Del aire, de los ríos, del SIDA, del discurso, del pensamiento. La contaminación no es necesariamente perjudicial, ni exclusiva de la actividad humana. En Venus, donde no hay ni una fábrica, la atmósfera está saturada de dióxido de carbono. Marte se secó sin conocer el dólar. La contaminación puede entenderse como la corrupción de la pureza física o abstracta. Y no es que antes de Jena gobernara la puridad (salvo en el mito edénico y otras fabulaciones), sino que la ultra-historia se resigna a esa utopía, aunque lo disfrace. Más aun: la era científico-industrial asimila el beneficio del contagio, lo promulga en apariencia; en la modificación genética y la ingeniería de materiales, en la transdisciplinariedad académica y la globalización, en la interconexión de mercados ${ }^{13}$. Sin embargo (y ahí es donde reside la paradoja), se resiste a la mezcla mediante formas de racismo, xenofobia, celos en las fronteras epistémicas, en la distribución draconiana de la riqueza (que evita el contagio entre ricos y pobres, salvo contadas excepciones que validan la regla y la ilusión post-histórica), y en la separación de poderes, fundamento político del liberalismo. Las nociones de ficción y realidad no escapan a esta contaminación paradójica, al "espíritu de época" de la ultra-historia. Jacques Ranciére (2011) explica el fenómeno en relación al zeitgeist:

El espíritu de análisis que [separa] la razón del mito y la historia de la ficción [es] la expresión de un mundo en el que las funciones se separan, en que el Estado no se funda sobre la filiación divina sino sobre las necesidades racionales de la administración de las poblaciones, en que las fuerzas de la industria le han arrebatado las ninfas y los faunos a la naturaleza, y en el que las leyes del valor del mercado han relegado a los otros valores en la esfera del comportamiento individual [...]. (35)

Ranciére señala, muy a tono con la línea marxista ${ }^{14}$, que el cambio en la estructura económica (capitalismo liberal) modeló el sensorium epocal e insufló el zeitgeist. Que tal como en la contabilidad empresarial, fue preciso discernir lo real de lo especulativo, lo contable de lo hipotético, lo cotejable de lo intangible, y esa lógica se instaló también en la recepción de los discursos literarios e históricos, y por tanto, en la comprensión del principio de realidad y del principio de ficción.

Pilar García (2018) explica que este deslinde de discursos ocurre en el siglo XVIII, cuando se reactualiza la noción aristotélica de inventio, asociado al elemento maravilloso, irracional, imaginario en las tramas. "Desde ellas [se refiere a las poéticas y estéticas prerrománticas] arranca el argumento que identifica la ficción con la dimensión estética de las obras literarias, como percepción y experiencia de la belleza" (49).

Las poéticas y estéticas del período, junto al espíritu "de un mundo en el que las funciones se separan", no supieron lidiar con la naturaleza ambigua de la ficción, con la incertidumbre cuántica de la ambivalencia. La "pretensión de verdad", al no conseguir discernir la "verdad" de la "mentira" en este tipo de discursos, entiende que la verdad -cuando aparece- está contaminada, y por tanto, resulta falsa. Tal razonamiento condujo a la igualación entre lo ficticio y el inventio, lo imaginario y maravilloso, a la preeminencia del cariz lúdico-decorativo de la ficción, en detrimento de su arista referencial e histórica, "cotejable". El pensador David Hume (1711-1776) resultó uno de los impulsores de esta idea.

${ }^{13}$ La inflación en Turquía, tras sucesivos rebotes financieros, devalúa el peso argentino durante 2018. La explosión del fracking en Estados Unidos desploma el precio del petróleo en 2013, y (junto a otros factores) precipita la hiperinflación y crisis en Venezuela.

14 Karl Marx (1859) explica la relación entre la economía (en particular las relaciones de producción) y la manera cómo el humano comprende a la sociedad y a sí mismo: "El modo de producción de la vida material condiciona el proceso de la vida social política y espiritual en general. No es la conciencia del hombre la que determina su ser sino, por el contrario, el ser social es lo que determina su conciencia” (Versión digital). 
La noción humeana de la ficción se desprende de su propuesta teórica sobre la historia y el conocimiento. Para el filósofo escocés, lo que distingue al discurso científico del ficticio es "la pretensión de verdad"; sin embargo, concibe la incapacidad del texto para expresar, por sí mismo, la pertenencia a uno u otro campo. O dicho en otras palabras: Hume no detecta ninguna marca textual que permita discernir lo "verdadero" de lo "falso", la "verdad" de la "mentira", lo cual resulta un problema en su afán separatista. Llegó a esa conclusión tras realizar un experimento de recepción. Le entregó a una amiga las biografías Las vidas paralelas, de Plutarco, y le advirtió que todo lo escrito ahí era imaginado. Ella las leyó interesada hasta toparse con dos referentes conocidos (Alejandro Magno y Julio César); al percatarse que Hume la había engañado, abandonó la lectura y le devolvió los ejemplares irritada.

La experiencia demostró al filósofo que, sin importar si el texto se asume como histórico o ficticio, el lector recibe "las mismas ideas y en el mismo orden" (Hume, 1981: 98), y lo que define la asimilación de una u otra forma es el pacto de veracidad asumido con el lector. Lo que Hume considera como real, verdadero, histórico, depende de la "cotejabilidad" del referente, y esa es la condición que distingue a un discurso de otro: "El principio general de este acuerdo que rige para el discurso histórico, es que las palabras (el texto), que despiertan en nosotros ideas, se correlacionan con el mundo. Y esta es la convención rota en las ficciones" (Mudrovcic, 2005: 36). Si para Hume y los filósofos de su tiempo la ficción (por su componente imaginario) no se "correlaciona" con el mundo ${ }^{15}$, no es por la naturaleza de la ficción, sino por el concepto de mundo prevaleciente. La ficción solo se reivindica al ampliarse las fronteras del "mundo", cuando se flexibilizan e incorporan nociones intangibles. Las concepciones de Ludwig Wittgenstein en el Tractatus Logico-Philosophicus (1921) abrieron las puertas al regreso definitivo de la ficción a la "realidad", y a la aparición de teorías que resitúan el problema ontológico de lo ficticio.

Los tres primeros aforismos del Tractatus burlan el abismo entre el inventio y lo "referencial-cotejable", trazan el puente entre lo real y lo imaginario (dimensión "problemática" de la ficción), y generan las premisas sobre las que se erigirán, directa o indirectamente, los postulados posteriores de Hayden White, Paul Ricoeur, Gérard Genette, Siegfried Schmidt, entre otros. Para Wittgenstein (1981):

1.Die Welt ist alles, was der Fall ist (El mundo es todo lo que acaece) ${ }^{16}$.

2.Was der Fall ist, die Tatsache, ist das Bestehen von Sachverhalten (Lo que acaece, los hechos, es la existencia de estados de cosas) (7).

3.Das logische Bild der Tatsache ist der Gedanke (Una representación lógica de hechos es un pensamiento) (18).

La revolución de Wittgenstein viene de comprender al mundo (la realidad) como "todo lo que acaece", y lo que acaece (hechos), como un "estado de cosas". O sea, para pertenecer al "mundo", Wittgenstein no discrimina entre hechos hipotéticos o consumados, imaginarios o histórico (se refiere a "alles", todo), y aquí es donde se desmorona el concepto reduccionista de ficción (heredado del siglo XVIII), que propugna la incompatibilidad y exclusión mutua entre realidad y ficción.

Más aún: Wittgenstein se refiere a la Sachverhalten ${ }^{17}$, que por un lado refiere a un concepto clave en lingüística ${ }^{18}$ (y la ficción se conforma, perpetúa y reproduce en el lenguaje); y por otro, implica un "plural en relación" (el estado de cosas es una situación circunstancial de objetos vinculados), y la ficción es una relación entre signos y referentes (en tanto lenguaje), entre imaginación y lenguaje (en tanto inventio), y

${ }^{15}$ María Inés Mudrovcic (2005), al explicar la propuesta humeana, refiere que el filósofo aceptó la confluencia entre la realidad y la ficción, el discurso histórico y el ficticio, en un punto muy particular: el de la narración histórica (luego las teorías textualistas del siglo XX retomarían esta idea): "Dado que el historiador deber reconstruir «la serie de acciones en su orden inicial... intenta en su relato tratar cada eslabón de esta cadena». Sin embargo, encuentra blancos que debe llenar, por lo que «suple por conjetura aquello de lo que no tiene conocimiento, y siempre tiene conciencia de que, cuanto menos inconexa sea la cadena que presenta a sus lectores, más perfecta es su obra» (I. 34). Y es allí donde la imaginación suplementa los datos de la memoria imponiendo coherencia al relato. (38).

${ }^{16} \mathrm{La}$ traducción es propuesta en el sitio wikisource.org (https://es.wikisource.org/wiki/Tractatus_Logico-Philosophicus), consultado el 10 de septiembre de 2018.

17 Sachverhalten puede traducirse, también, como "contexto" y “circunstancia”, según el diccionario alemán-español Pons (https://es.pons.com/traducci\%C3\%B3n/espa\%C3\%B1ol-alem\%C3\%A1n).

${ }^{18}$ En 1934, Karl Bühler asume esta categoría en su obra Teoría del lenguaje (Sprachtheorie), que recupera el modelo del órganon, propuesto por Platón. Para Bühler, los signos o fenómenos acústicos concretos (Zeichen) se vinculan con los objetos y estados de cosas del mundo (Gegenstände und Sachverhalte), que son entes extralingüísticos. Al operarse esta conexión, el lenguaje manifiesta su naturaleza representativa (Darstellung). 
entre inventio e historia (en tanto arquetipo mítico, según Frye y White ${ }^{19}$ ). O sea, estos rasgos de la fícción que son "existentes" (Bestehen), configuran una relación, un "estado de cosas" (Sachverhalten) que conforman hechos (Tatsache), y la ocurrencia de hechos (was der Fall) es el mundo (Die Welt).

El paroxismo de esta lógica, que integra la ficción (incluida su arista imaginativa) al "mundo real", lo aporta el aforismo 3 ("una representación lógica de hechos es un pensamiento"): las tramas ficcionales ${ }^{20}$, en tanto representación coherente de una ficción (hecho), es un pensamiento. Pero un pensamiento, en tanto "estado de cosas existente", es también un "hecho", y por tanto, pertenece al mundo. En resumen, según el razonamiento wittgensteiniano aplicado al problema ontológico de lo ficticio, podemos deducir que la ficción posee la extraña propiedad de ser simultáneamente hecho (Tatsache) y pensamiento (Gedanke): hecho al constituirse como "un estado de cosas existente" que relaciona al inventio, el referente y el lenguaje; y pensamiento al "representar lógicamente" un arquetipo mítico. La ficción-pensamiento, el interactuar con el lenguaje, deviene ${ }^{21}$ en trama ficcional, y la trama ficcional también posee la doble naturaleza wittgensteiniana: hecho (al conformar un estado de cosas existente compuesto de personajes, acciones, tiempos, objetos imaginarios), y pensamiento al representar lógicamente el hecho ficcional. Esa propiedad especial de la ficción, su valencia simultánea como hecho y pensamiento, como objeto y representación, como realidad consumada y realidad hipotética, resulta el eje de la creación literaria del siglo XX (de Borges al Boom, al realismo socialista y al testimonio, al neopolicial iberoamericano y las autoficciones) y de buena parte de la teoría literaria y comunicológica (Luckacs, Genette, White, Martínez Bonatti, Eco, Barthes).

Tras el final de la Primera Guerra Mundial (epílogo de Jena) y hasta el derrumbe del Muro de Berlín (el "siglo XX corto" del que habla Hobsbawn), el problema de la ficción vivió el desplazamiento entre dos polos: de las posturas humeanas y positivistas antes mencionadas, a la exacerbación postmoderna de lo ficticio, donde "la realidad y la verdad resultan inalcanzables", por lo que "todo es ficticio o, lo que es lo mismo, todo es real, y en consecuencia cualquier cosa vale y de forma indistinta" (Alberca, 2007: 285). Entre un extremo y otro hubo propuestas "intermedias", conciliatorias, que derivaron la discusión hacia la filosofía de la historia. Particularmente relevantes resultan las de Gerard Genette, quien a pesar de enfatizar en la función estética del discurso ficcional (en línea con el sensorium previo), legó una batería conceptual que liberó a la ficción del "terreno parasitario", de la reclusión en el monasterio del inventio. Y Hayden White, que aunque consideró a la ficción como "una suspensión de la realidad", una "operación tropológica" (García, 2018), relativizó la separación entre realidad y ficción al desarrollar las teorías textualistas de la historiografía.

En el caso de White, no es que haya atraído la ficción al mundo, que haya indagado y resituado el carácter referencial/cotejable de lo ficticio para legitimarlo en la realidad, sino que al cuestionar el principio de certidumbre de la Historia reconfigura lo que entendemos por "realidad", le desdibuja las fronteras rígidas y la vuelve más compatible con la noción aristotélica de inventio. No obstante, su propuesta transgresora abrió paso al consenso actual sobre la ficción, signado por el influjo postmoderno, por los rasgos distintivos de la ultra-historia (el individualismo gregario y el simulacro), y por el fracaso de los grandes proyectos utópicos del siglo XX. Estos debates han posibilitado replantear la ficción allende al terreno literario, para entenderla como un "hecho" y "pensamiento" constituyente de la vida contemporánea, más allá de la narración lúdicoestética, y presente en las actividades cotidianas (desde pagar con una tarjeta de débito, leer el último pasquín sobre la celebridad de turno o revisar los perfiles de redes sociales). La chilena Pilar García (2018) resume el consenso actual en torno a la ficción acorde a esta línea. La describe como "uno de los modos fundamentales de expresión, comprensión y conocimiento, entendidos como universales poéticos", y apunta a la Historia y la Poesía (lo consumado y lo hipotético) como el primer binomio de estos universales, "en la medida que encarnan la doble oposición: de lo posible a lo efectivo y de lo general a lo particular" (40-43).

\footnotetext{
${ }^{19}$ Para White, "el argumento en torno a la ficción es circular: el elemento ficcional es la estructura de trama mítica, pues detrás de cada relato hay alojado un mito [...] Aquí White sigue a Frye: «las ficciones son, en parte, sublimaciones de estructuras míticas arquetípicas» (White 2003: 111)" (García, 2018: 54).

${ }^{20}$ La trama, en este artículo consideradas en función de las ficciones (por eso trama ficcional) corresponde a “operaciones o procedimientos (teckné) inherentes a los modos de expresión de la experiencia temporal viva y a la construcción de sentidos a través del relato" (García, 2018: 42).

${ }^{21}$ En el sentido deleuziano de "boda contranatura", de captación y asimilación de un gen de naturaleza ajena.
} 


\section{Autoficciones: una propuesta rizomática entre Literatura, Capitalismo e Historia}

Las "escrituras del yo" son los géneros literarios que más potencian el rasgo bivalente de la ficción como "hecho" (Tatsache) y "pensamiento" (Gedanke). O lo que es igual: que más tensan la oposición del binomio de universales Historia-Poesía. Los mejores autores provocan el estallido de esa cuerda, y sus textos constituyen la huella del quiebre, la fuga literaria. La ficción-hecho es la onda expansiva que se propaga desde la fisura mítica ${ }^{22}$, en todas direcciones, y pulveriza los objetos de la Historia y los objetos de la Poesía. La ficción-pensamiento moldea esos despojos: de su interacción con el lenguaje surge la trama, de su adecuación al tiempo la narración.

Las autoficciones resultan un tipo peculiar (tal vez el más potente) de estas explosiones ficcionales. Lo que implica la condición de "auto" es el testimonio de los sobrevivientes, la narración subjetiva de la catástrofe, la reconstrucción de la experiencia usualmente traumática. También la responsabilidad de diseñar, construir y detonar el artefacto literario; de ahí la arraigada comprensión de esta escritura como un posible intento de suicidio, o de asesinato del "yo" y otras víctimas colaterales, pues el autor autoficticio suele invocar en su rito a una legión de conocidos. Para escribir este tipo de textos:

[...] hay que estar dispuesto a desollarse. Te desuellas, te despellejas, quedas en carne viva, y entonces te lanzas por el despeñadero de la novela hasta el fondo del precipicio. Golpeándote, descuerándote y quebrando tus huesos contra las rocas. Es el único modo. El que no se atreva a hacerlo así, es mejor que deje el papel y los lápices sobre la mesa y se dedique a vender tomates o al negocio inmobiliario. (Gutiérrez, 2016: 73)

Lo afirma el escritor cubano Pedro Juan Gutiérrez, en Animal Tropical, considerada por Manuel Alberca un ejemplo de autoficción hispanoamericana. Alberca (2007) comprende a este género como un "original espacio autobiográfico y novelesco", donde se imbrican "datos biográficos y elementos inventados" para hacer confundir, de manera más o menos consciente, al autor y al personaje, o "en hacer de la propia persona un personaje, insinuando, de manera confusa y contradictoria, que ese personaje es y no es el autor" (32).

El teórico español retoma el neologismo autofiction, propuesto por Serge Doubrovsky en 1977, y le añade dos premisas sobre las que elabora su propuesta: 1) la autoficción se territorializa en un espacio intermedio entre la novela y la autobiografía, asume rasgos de ambas, tanto en lo formal como en la "pretensión de verdad". Esa vacilación entre los hechos "probables" y los hechos "consumados" genera un pacto de lectura ambiguo, donde resulta imposible distinguir lo imaginario de lo histórico. 2) "[...] la identidad visible o reconocible del autor, narrador y personaje del relato" (2007:31), con énfasis en los rasgos onomásticos que demuestren la coincidencia. Ana Casas (2012) sigue esta línea, aunque flexibiliza la condición onomástica y acepta a los paratextos como modo de "refrendar" el vínculo autor/personaje, así como los elementos factuales (11).

La crítica predominante sobre la autoficción parece centrada en el problema realidad/inventio en los relatos. Como tendencia, consensuan la indiscernibilidad de su constitución: el polvo de los objetos de la Poesía y de la Historia, al moldearse, acaso por el calor de la explosión ficcional, se alean en mezcla indescifrable, generan un terreno ambivalente donde las leyes cuánticas predominan sobre la lógica cartesiana. "Los relatos autoficticios -advierte Alberca- desplazan los límites estables que separan [...] la ficción de la historia, para tender puentes y crear fusiones entre estos territorios que, de manera solapada o discreta, señalan un campo de posible innovación" (2007: 252).

El entendimiento de la autoficción como un "territorio" de "leyes ambivalentes" posibilita un enfoque bastante inexplorado: la integración del universo cuántico (particularmente las nociones del principio de incertidumbre), con las propuestas deleuzeanas del mundo rizomático, que enfatiza en la "conexión de heterogéneos" y en la estratificación de territorios ambiguos "devenidos" tras fugas y reterritorializaciones. Esta posibilidad resulta mayoritariamente soslayada, pues el grueso de los análisis sobre la autoficción (Doubrovsky, Alberca, Miraux, Casas, Ricouer) parten de la lógica del pensamiento arborescente, fundado por Descartes y sintetizado por Newton, cuya expresión histórica resulta el liberalismo propuesto por Locke,

${ }^{22}$ En la zona cero de la explosión ficcional hay un aparente vacío que en realidad es la condensación "atómica” del mito. El mito, siguiendo a Hayden White y Northrop Frye, es la carga detonada durante la ficción. Esta concepción del mito como aparente vacío o silencio se remonta al siglo XVIII, cuando Giambattista Vico presentó un cuestionado recurso etimológico en su obra Principios de la ciencia nueva (1725): "La fábula griega se llama también muthos, de donde procede el mutus latino, fábula que era mental en los tiempos mudos, la cual, según Strabón, existió antes que la lengua articulada o vocal" (Ballaci, 2015: 202). 
teorizado por la Ilustración, impuesto por Napoleón y consolidado con las bayonetas de la Triple Entente; un tiempo que se expresa literariamente a través de las novelas, las memorias, las autobiografías. Esta línea de pensamiento, hija del espíritu de un mundo donde "las funciones se separan", aun en sus manifestaciones más avanzadas (Genette, White, el propio Alberca, para quien "la ficción y la historia poseen fronteras estables") perciben como problemática la indiscernibilidad de lo ficticio: la asunción de la ambigüedad constituye la resignación ante lo indescifrable, la capitulación de la lógica arborescente a un "hecho" que excede su capacidad de representarlo ("pensarlo"). Este instrumental, desde su propia tradición teórica, se ve superado por un fenómeno hijo de otro tiempo (la ultra-historia más reciente ${ }^{23}$ ) y que opera bajo las leyes de otro universo: aunque las propuestas de Wittgenstein abren el umbral, las autoficciones no operan en el mundo de Newton, sino en el de Einstein, donde no se separan las expresiones físicas básicas (el tiempo y el espacio), sino que se integran en una misma unidad (el espacio-tiempo) cuya curvatura posible genera ambivalencias, "absurdos coherentes"; la expresión literaria de este mundo (al menos en Latinoamérica) la inaugura Borges, la potencian algunos autores del Boom (como Cortázar) y la continúan los escritores autoficcionales contemporáneos.

Sin forzar la teoría, puede identificarse cómo los textos literarios replican los rasgos que Deleuze y Guattari (2004) confieren a los rizomas, cómo los textos literarios construyen rizomas y se convierten en uno. "Lo múltiple hay que hacerlo, pero no añadiendo constantemente una dimensión superior, sino [...] a fuerza de sobriedad, al nivel de las dimensiones de que se dispone, siempre n-1 (sólo así, sustrayéndolo, lo Uno forma parte de lo múltiple)" (12). Eso es lo que Deleuze y Guattari comprenden por rizoma: la generación de multiplicidad a partir de la simplificación, de restar, en vez de añadir. Cuando el rasgo físico distintivo de Auxilio Lacouture resulta su peculiar dentadura, Bolaño induce la diferenciación de su personaje al sustraer una dimensión (los dientes). La ausencia de dientes genera la multiplicidad, la individualización respecto a la norma general. El procedimiento se repite en la construcción de Carlos Coffeen Serpas: lo que lo distingue de otros artistas (incluyendo a Auxilio, Arturo Belano y los jóvenes poetas) es que prescinde del "ambiente cultural", de la bohemia mexicana, para enclaustrarse en la creación. Se anula, y en esa anulación, en ese vacío de mundo, radica la particularidad: al diferenciarse de la norma, genera multiplicidad, expansión de mundo, elongación del rizoma.

El rizoma se rige por principios que, como insinuamos, encuentran una correlación en los textos literarios $^{24}$. En la literatura existe un funcionamiento rizomático en tanto se conectan los heterogéneos: personajes con lugares, lugares con objetos, objetos con acciones, discursos, etc. ("cualquier punto del rizoma puede ser conectado con cualquier otro, y debe serlo"); en cuanto generadora de multiplicidades: "una multiplicidad no tiene ni sujeto ni objeto, sino únicamente determinaciones, tamaños, dimensiones" (2004: 14), a tono con la pregonada "muerte del autor" (no hay sujeto que escriba o lea) y con la ambigüedad de la ficción (disolución de los objetos). El principio de ruptura asignificante contempla que "un rizoma puede ser roto, interrumpido en cualquier parte, pero siempre recomienza según ésta o aquella de sus líneas, y según otras" (15), como ocurre con los personajes ficcionales (el Arturo Belano de Bolaño, el Pedro Juan de Pedro Juan Gutiérrez), con ciertas tramas ficcionales (la historia de Carlos Wieder en Estrella distante retoma y prolonga el relato de Ramírez Hoffman en La literatura nazi en América). El $5^{\circ}$ y $6^{\circ}$ principios (la cartografía y la calcomanía), aluden a la naturaleza inasible de los rizomas y su representación, a la imposibilidad de modelar una estructura que los prefigure o contenga. "El mapa es abierto, conectable en todas sus dimensiones, desmontable, alterable, susceptible de recibir constantemente modificaciones" (17), en tanto el calco resulta la imitación inexacta del mapa: "no es rigurosamente exacto que un calco reproduzca el mapa. Un calco es más bien como una foto, una radiografía que comenzaría por seleccionar o aislar lo que pretende reproducir" (18). El mapa, "totalmente orientado hacia una experimentación que actúa sobre lo real" (17), puede identificarse con la ficción-Tatsache, que aloja un mito y lo transforma, actividad mimética, creadora y dinámica. La trama ficcional constituye el calco de ese "hecho", la fotografía de la ficción (su Gedanke), o más profundamente: la radiografía del mito que aloja la ficción. Eso explica que las tramas, los textos, resulten estáticos (las líneas no se trenzan y crean nuevas historias o hechos, las palabras permanecen ordenadas); mientras las ficciones (mapas desmontables y alterables) se transformen sistemáticamente y dan

\footnotetext{
${ }^{23}$ Alberca sitúa en la década de 1970 la "extraordinaria expansión de la literatura autobiográfica en todas las literaturas occidentales", en consonancia "con los designios de una sociedad guiada por el prestigio y predominio de lo individual" (2007:31). Sin embargo, otros textos clásicos evidencian rasgos muy semejantes a las autoficciones. Tal vez el caso más emblemático lo constituya La divina comedia (1304-1321), de Dante Alighieri.

${ }^{24}$ Para mayor profundidad, revisar los Principios del Rizoma propuesto en Mil mesetas, entre las páginas 13 y 20 aproximadamente.
} 
cuerpo a nuevas tramas, nuevos relatos, que reproducen el mismo núcleo mítico y devienen ficciones emparentadas: el relato de la inmaculada concepción de Jesús reproduce el mito egipcio de la procreación virginal de Horus, dios del sol; la historia del Arca de Noé repite el relato del barco de Ziusudra, narrado en el Poema de Gilgamesh siglos antes de la Biblia.

Las autoficciones, en tanto textos literarios, asumen el comportamiento rizomático. La particularidad respecto a otros géneros resulta la dimensión sustraída (n-1): la distancia entre autor y narrador, y entre autor y personaje. El rizoma autoficcional no derrumba el puente que une las categorías: devora el espacio que las separa. La fundición de los tres cuerpos resulta de ese vacío: el vacío los atrae como un agujero negro. El otro rasgo distintivo de la autoficción (imbricación realidad/inventio), puede explicarse desde los territorios híbridos que generan la interacción de universales (Historia y Poesía): la literatura "no es una imagen del mundo, [...] hace rizoma con el mundo, hay una evolución aparalela del libro y del mundo, el libro asegura la desterritorialización del mundo, pero el mundo efectúa una reterritorialización del libro" (Deleuze, G y Guattari, F: 2004: 15). Desterritorialización cuando Arturo Belano (libro) asume los eventos que ocurrieron a Roberto Bolaño (mundo): emigra a México en la infancia, detenido en Chile tras el golpe militar. Reterritorialización en el mito biográfico de Bolaño y Concepción (mundo) tras la escritura de Estrella distante (libro). Historia aparalela en tanto Arturo Belano "vive" en cada lectura, y Roberto Bolaño pone su punto final en 2003.

La autoficción, cualquier texto literario compuesto de manera rizomática, se construye desde la sustracción de dimensiones de mundo. El rizoma, en su expansión, demuestra poseer una "cuchilla", un borde filoso que aniquila las dimensiones que intercepta. De lo contrario, ¿cómo se efectúa el n-1?, ¿cómo puede borrarse una dimensión sin dejar más rastros que su ausencia?, ¿qué energía descompone las fronteras y estremece los territorios hasta hibridarlos? Deleuze y Guattari no alcanzan a explicarlo, y aunque se precisaría un análisis más exhaustivo, me inclino a pensar que esa energía o "cuchilla" del borde rizomático se halla en el carácter destructivo ${ }^{25}$.

Lo que define al carácter destructivo es la pulcritud de su corte, de ahí su demanda como aditamento maquínico ${ }^{26}$. Y su abundancia natural. "El carácter destructivo sólo conoce una consigna: hacer sitio; sólo una actividad: despejar. Su necesidad de aire fresco y espacio libre es más fuerte que todo odio" (Benjamin, 1931: versión digital). El carácter destructivo es omnipresente ("este es el gran vínculo que enlaza unánimemente todo lo que existe"), y tan eficiente como la bomba atómica, pero limpio: "el carácter destructivo borra incluso las huellas de la destrucción". Quizás el mayor rasgo rizomático del carácter destructivo radique en su modo de expansión desestructurada y anti-arborescente:

El carácter destructivo no ve nada duradero. Pero por eso mismo ve caminos por todas partes. Donde otros tropiezan con muros o con montañas, él ve también un camino. Y como lo ve por todas partes, por eso tiene siempre algo que dejar en la cuneta. Y no siempre con áspera violencia, a veces con violencia refinada. Como por todas partes ve caminos, está siempre en la encrucijada. (Benjamin, 1931)

El carácter destructivo, en términos físicos, está compuesto de antimateria. Por eso su efectividad al pulverizar dimensiones. En los vacíos que provoca, la naturaleza suele replantar un germen. De ahí que el carácter destructivo, en su contracara, tribute a la creación. El estallido monárquico de 1789 (el cráter de ese estallido) alojó el embrión liberal que pululaba en la mente de Locke y la Ilustración. Sin el terror de Robespierre Napoleón no habría ascendido, y Jena no fuese más que un pueblo innombrado de la llanura germana, semejante a Eichsfeld, o Greiz, o Sonneberg. Si Jena significa algo para la Historia Universal lo debe al carácter destructivo (tanto al residual de 1789 y 1793, como a la propia naturaleza destructiva del combate). Quizás Hegel había adelantado la contracara del concepto benjaminiano, al predecir que toda "desestructuralización genera una estructura nueva". El carácter destructivo enlaza todo cuanto existe. En la explosión ficcional, conforma la pared de choque de la onda expansiva: conecta los dispares objetos de la Poesía y la Historia, en direcciones simultáneas y azarosas. El carácter destructivo enlaza, también, los Hechos y los Pensamientos: en la omisión de frases y proposiciones que enturbian el vínculo entre los entes (al representar el hecho "sol", se omiten las proposiciones oscuro, frío, etc.).

En literatura, ciertos textos potencian el sistema rizomático (n-1) y el protagonismo del carácter destructivo. José Saramago construye Ensayo sobre la ceguera desde la sustracción de una dimensión: la

\footnotetext{
${ }^{25}$ Concepto propuesto por Walter Benjamin en Discursos interrumpidos (1931).

${ }^{26} \mathrm{El}$ Anexo 2 propone una máquina ficcional de factura wittgensteiniana.
} 
vista. El universo de esa obra gira en torno a la ausencia de visión: el vacío atrae a las otras dimensiones y las modifica. El "mundo" se desplaza en función del agujero masivo, y la ficción radica en el rastro de ese desplazamiento. Borges fuerza al método hasta el límite en Funes el memorioso: construye una autopista de doble vía. El personaje recuerda absolutamente todo, momento a momento, y esa imposibilidad de olvidar provoca la desgracia. Formalmente, el relato se construye sobre la sustracción de una dimensión (el olvido); pero temáticamente propone un universo que carece de carácter destructivo: lo que falla en la memoria de Funes es la capacidad de omitir, de "hacer sitio" y "despejar". Al eliminar una dimensión de carga negativa, Borges genera una materialidad que, por inasumible, resulta destructiva. Se rige por el principio matemático de que los negativos, al multiplicarse, producen positivos $(-1 \mathrm{x}-1=1)$.

En las autoficciones, el carácter destructivo posee dos funciones definitorias para el género: primero, "borra" las distancias entre autor y narrador y entre autor y personaje, lo que posibilita la univocidad de las tres figuras; segundo, edita la memoria, recorta tamaños, omite líneas y hechos que son modificados y resignificados al traerse al presente en la paratopía ${ }^{27}$. Musitano (2016) llama a ese proceso "potenciación de los mecanismos del recuerdo en detrimento del carácter sistemático y organizativo de la memoria" (105), y lo considera un rasgo distintivo de la autoficción.

La autora argentina propone el deslinde entre Memoria y Recuerdos. Mientras una se encarga "de transformar la vida en relato, de ordenar, de dar sentido a una historia" (Musitano, 2016: 114), los otros "están representados como imágenes de una vida pasada" (115). Podemos presumir que el carácter destructivo opera sobre esa imagen, la difumina y transforma al borrarle líneas. Los inventios suelen ser los esfuerzos de los autores por reconstruir tales omisiones: los trazos "erráticos" al recomponer el pasado. "Hay en el recuerdo un poder alucinatorio del deseo que cuestiona una realidad. Los hechos son recordados tal como nunca ocurrieron y allí es donde aparece lo incierto, lo impersonal" (N. Rosa en Musitano, 2016: 115). Ahí radica la mayor naturaleza "ficcional" de la autoficción; lo que, además, resulta inevitable.

Musitano, incluso, propone una tesis que ratifica la idea del carácter destructivo como configurador del género. "La autoficción se basa en la posibilidad de presentificar lo perdido desde lo imaginario del recuerdo" 28 (2016: 122). Lo perdido (a manos del carácter destructivo) genera un vacío, un agujero negro que atrae el deseo y las acciones (escriturales) para recuperarlo. Acaso la nostalgia sea el sentimiento que percibimos los humanos y que encarna ese deseo; y las autoficciones, como toda "escrituras del yo", suelen estar motivada por la nostalgia, por la añoranza de "presentificar lo perdido" "29. Los textos autoficcionales pueden entenderse como la "presentificación" inexacta de lo perdido, así como la manera de intentar satisfacer al deseo nostálgico. El carácter destructivo (el olvido, lo perdido) constituye el detonante del mecanismo autoficcional. La ausencia genera una presencia inexacta de lo ausente. Hegel lo había previsto en su dialéctica. El hecho (tesis) y su ausencia (antítesis) devienen en una autoficción potenciada por el recuerdo (síntesis).

\section{Conclusiones}

La autoficción es un género hijo de la ultra-historia (si obviamos la excepción dantesca). En los anillos de su tronco -aún joven- encontramos las huellas de la atmósfera creativa de su tiempo, del "clima intelectual, estético, ético y artístico" de la época. Alberca habla del género como resultado de la "individualidad gregaria" y la "majestad del simulacro", dictámenes de la sociedad capitalista occidental. Sin embargo, reconoce que estos textos se encuentran ligados a "la quiebra del poder representativo de las poéticas realista [...], pues aunque tienen una apariencia realista convencional, en el fondo cuestiona y subvierte de manera sutil, pero efectiva, los principios miméticos" (2007: 50).

${ }^{27}$ Dominique Maingueneau identifica que el autor, al intentar contar su experiencia de mundo, se aísla, y que en ese aislamiento es donde se vinculan los objetos de la Poesía y los objetos de la Historia en la construcción de ficciones. "La pertenencia al campo literario no es la ausencia de todo lugar, sino más bien una difícil negociación entre el lugar y el no-lugar, una localización parasitaria que vive de la propia imposibilidad de estabilizarse. Llamaremos paratopía a esa localidad paradójica" (Miraux, 2005: 33). En la metáfora de las explosiones ficcionales, la paratopía sería la cápsula de acero donde se conecta el amasijo de cables, la carga y el cronómetro que detona el núcleo mítico.

${ }^{28}$ El énfasis es propio.

${ }^{29}$ Miraux (2007) propone dos tipos fundamentales de escrituras del yo: la picaresca y la elegiaca. En la segunda, "los primeros capítulos [...] reproducen una cosmogonía feliz, un tiempo pasado en que la inocencia del yo, la promesa de una vida abierta a todas las posibilidades, seguramente de ilusiones múltiples, constituyen añorados instantes de júbilo" (43). Las escrituras del yo de las últimas décadas parecen privilegiar este modelo de "añoranza" antes que los textos picarescos. 
Alberca advierte en las autoficciones una complicidad con el sistema donde se producen. Las considera "una biografía a la carta" en sintonía con "el modelo de conducta de la sociedad" (2007: 284). Pero, a la vez, les reconoce un carácter subversivo. Acaso porque, como predijo Newton, "con toda acción ocurre siempre una reacción igual y contraria". O lo que es igual: la idea foucaultiana de que todo poder engendra un contrapoder, una resistencia. Tal vez por eso los personajes autoficticios suelen ser marginales, en situaciones precarias, inmersos en un proceso involutivo de corte deleuzeano. En plena fuga. En la autoficción, el protagonista difícilmente sueñe con instalarse en una oficina del piso 88 de las Torres Petronas, en el confort del asiento de terciopelo y los zapatos de cuero; más bien narrará en detalles el olor a aceite requemado de la venta callejera, la efervescencia de los suburbios de Kuala Lumpur y la comezón insoportable del hacinamiento. Ranciére (2011) alerta del rasgo subversivo en la literatura contemporánea. Señala que la literatura post-feudal "define una distancia con la escena política democrática" (39) -pilar político del liberalismo y que Hegel considera como punto culminante de la Historia-, por considerarla una falsa, una "puesta en escena":

A esta puesta en escena democrática, la literatura le opone otra política, cuyo principio es el de devolver a su vanidad el clamor de los oradores del pueblo [...], abandonar la escena de la palabra enunciada por las voces sonoras para poder descifrar los testimonios que la sociedad misma da a leer, para exhumar aquellos que ésta descarta sin quererlo ni saberlo en los bajos fondos. Al ruidoso escenario de los oradores se le opone el viaje por los mundos subterráneos, que conservan la verdad oculta. (39-40)

En el examen del tronco de la autoficción se hallan las huellas de la contaminación paradójica de nuestro tiempo: a la vez que reproduce el sistema, lo confronta. Acaso la autoficción, formalmente, se construye sobre el "individualismo gregario" y la "majestad del simulacro"; pero temáticamente, al exagerarlos ${ }^{30}$, lo parodia. Y la parodia siempre constituye una actitud subversiva que, junto a cuestionar el sistema, envía señales de su agotamiento.

La exploración del cuerpo autoficticio evidencia, también, la naturaleza rizomórfica del género, lo que abre un abanico bastante soslayado de posibilidades teóricas. Posibilita el examen de la ficción como mapa, y de la trama ficcional como calco. Esta analogía permite un enfoque distinto al problema de la ficción, descentra el debate teórico predominante - orientado al vínculo Historia-Poesía o inventio-referente como polos tendencialmente antagónicos-, para enfocarse en la relación complementaria, maquínica, entre Hecho (Tatsache) y Pensamiento (Gedanke). La perspectiva induce a considerar el "pacto ambiguo" como una reterritorialización/desterritorialización de los objetos de la Poesía y los objetos de la Historia; estos movimientos y contagios favorecen la comprensión del "pacto ambiguo" como fugas y devenires, lo que clarifica un tanto esta área neblinosa, usualmente considerada indescifrable y renuente a la disección. En el cuento Axolotl, de Julio Cortázar, a medida que el personaje deviene axolotl, la ficción deviene Poesía (en el sentido de los universales). Existe el desplazamiento de un hecho de la Historia ${ }^{31}$ hacia el terreno de la Poesía, hacia el inventio de "lo que podría suceder" (el devenir-pez). En la senda contraria hallamos Amuleto, particularmente al personaje de Auxilio Lacouture. La ficción parte de un hecho de la Poesía (las reflexiones de la mujer durante los 15 días de encierro en un baño de la Facultad de Filosofía y Letras de la Unam ${ }^{32}$ ), para reterritorializarse en los hechos históricos del Mayo del 68 mexicano y la Matanza de Tlatelolco. La ficción, en este caso, evidencia una inclinación hacia el devenir-Historia.

El último eslabón de esta propuesta rizomática lo constituye el benjaminiano "carácter destructivo". Su capacidad de sustraer dimensiones, de crear agujeros que fuerzan a oscilar al resto de los hechos ficcionales. La propiedad de "enlazar unánimemente todo lo que existe" conecta los dispares objetos de la Poesía y de la Historia: la tensión de esa boda contranatura alimenta la energía de las fugas (toda fuga es un movimiento, y todo movimiento requiere energía), la ruptura de las fronteras y la generación de territorios "ambiguos". El carácter destructivo también influye sobre los recuerdos, modificándolos, restándoles líneas, potenciando los

\footnotetext{
${ }^{30}$ Alberca aclara que en la autoficción la imagen de mundo resulta distorsionada por el exceso de los trazos de esa propia imagen. "[...] si hubiera que adscribir la autoficción a alguna estética precisa sería a la hiperralista [...]: exalta una apariencia extrema de lo real hasta prácticamente desrealizarlo. La autoficción, como las artes inspiradas en esta estética, nos confunde con su engañosa transparencia, pues el realismo de esta corriente plástica instituye una práctica que subvierte los pilares del realismo" (2007: 50).

${ }^{31}$ El universo propuesto es presumiblemente cotejable. El relato, narrado en primera persona, invita a identificar al personaje con el autor Julio Cortázar, quien vivió durante años en París. La mención a calles y direcciones exactas imita el estilo de una crónica periodística, lo que favorece el efecto de verosimilitud. Y en el Jardín des Plantes, efectivamente, existe un acuario que ha exhibido a esta especie animal.

${ }^{32}$ El encierro es un hecho históricamente comprobado, protagonizado por la poetisa y maestra uruguaya Alcira Soust Scaffo. Lo inventado resultan las reflexiones que Bolaño atribuye a la mujer, y que conforman la narración de la novela.
} 
trazos de relleno del autor, el inventio. Esta fuerza destructiva, al aniquilar, invoca la creación autoficticia: detona el mecanismo nostálgico que impulsa la "presentificación de lo perdido". Acaso toda historia autoficticia, en el fondo, no encierre más que el relato de la búsqueda de Ítaca.

\section{Referencias bibliográficas}

Agamben, Giorgio (2006). Lo abierto: el hombre y el animal. Buenos Aires: Adriana Hidalgo.

Alberca, Manuel (2007). El pacto ambiguo. De la novela autobiográfica a la autoficción. Madrid: Editorial Biblioteca Nueva.

Ballacci, Giuseppe (2015), "La ciencia de la historia de Giambattista Vico: entre modernidad y antigüedad, filosofía y retórica", Revista Diacrítica, 29(2), págs. 185-202.

Benjamin, Walter (1931). El carácter destructivo. Versión digital. Disponible en: http://www.theclinic.cl/2017/12/28/ensayo-walter-benjamin-caracter-destructivo/

Bolaño, Roberto (1999). Amuleto. Barcelona: Editorial Anagrama.

Casas, Ana (2012). La autoficción. Reflexiones teóricas. Madrid: Arco Libros.

Deleuze, Gilles; Guattari, Félix (2004). Mil mesetas: Capitalismo y esquizofrenia. Valencia: Pre-Textos.

Fukuyama, Francis (1992). El fin de la historia y el último hombre. Barcelona: Editorial Planeta.

García, Pilar (2018), "Literatura, historia: crisis de las disciplinas y contextos para la ficción", Revista de Literatura, enero-junio, vol. LXXX, $n^{\circ}$. 159, págs. 35-65.

Gutiérrez, Pedro Juan (2016). Animal Tropical. Santiago de Cuba: Editorial Oriente.

Hollier, Denis (1982). El colegio de sociología (1937-1939). Madrid: Taurus.

Hume, David (1981). Tratado de la naturaleza humana. Madrid: Editora Nacional.

Kojève, Alexandre (2013). Introducción a la lectura de Hegel. Madrid: Trotta.

Marx, Karl (1859), "Prólogo" a la Contribución a la crítica de la economía política. Versión digital. Disponible en: https://www.marxists.org/espanol/m-e/1850s/criteconpol.htm\# ftn2

Miraux, Jean Philippe (2005). La autobiografía: las escrituras del yo. Buenos Aires: Ediciones Nueva Visión.

Mudrovcic, María Inés (2005). Historia, narración y memoria: Los debates actuales en filosofía de la historia. Madrid: Ediciones Akal.

Musitano, Julia (2016), "La autoficción: una aproximación teórica. Entre la retórica de la memoria y la escritura de recuerdos", Acta Literaria 52, Primer semestre 2016, págs. 103-123.

Ranciére, Jacques (2011). Política de la literatura. Buenos Aires: Libros del Zorzal.

Verdú, Vicente (2003). El estilo del mundo. Barcelona: Anagrama.

Wittgenstein, Ludwig (2009). Tractatus Logico-Philosophicus. Madrid: Editorial Gredos. 


\section{Anexo I. Plano base de una explosión ficcional}

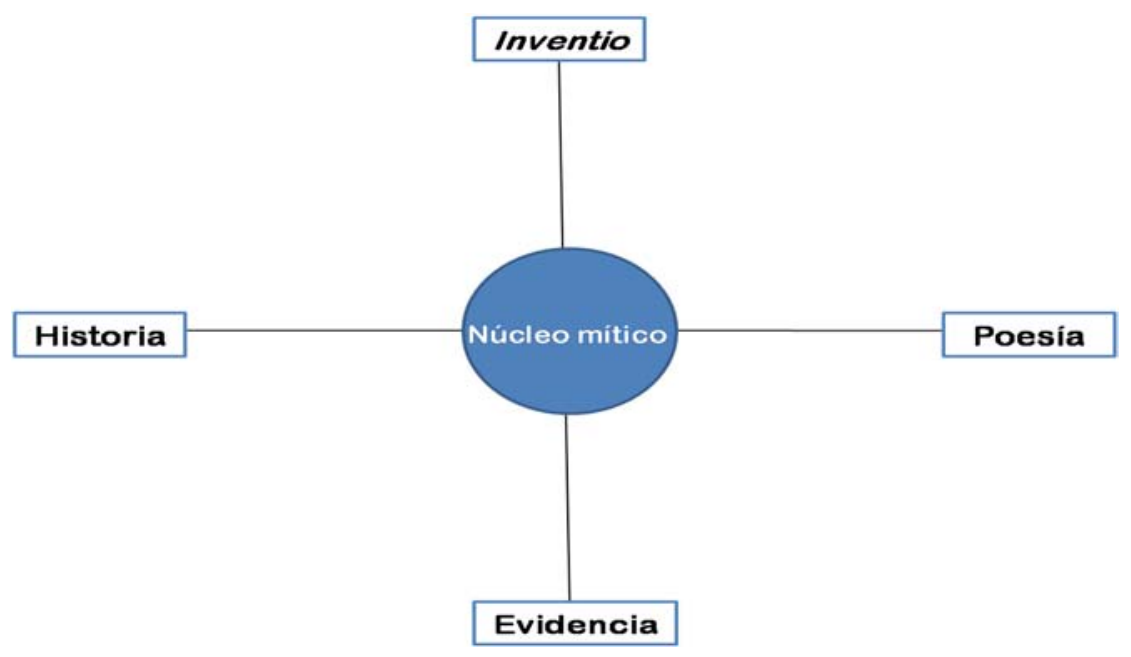

En las explosiones ficcionales, el núcleo mítico se disgrega en todas direcciones según el impulso detonante. En el centro, el mito, entendido como mutus, silencio. Solo el núcleo mítico, o el silencio, pueden estar desprovistos de alguno de los valores de Historia o Poesía (en tanto universales), y de pretensión de verdad (Inventio como imaginación o Evidencia). Todos los textos poseen algún valor en todas las dimensiones, solo que (según el género o el tipo de discurso) privilegian unos u otros. Esos valores no son cuantificables, sino solamente sugeridos a modo de intensidades. La explosión ficcional se representa como la integridad de todos los valores. Sirvan los siguientes textos a modo de ejemplificación:

a) Historia del siglo $X X$, Eric Hobsbawm

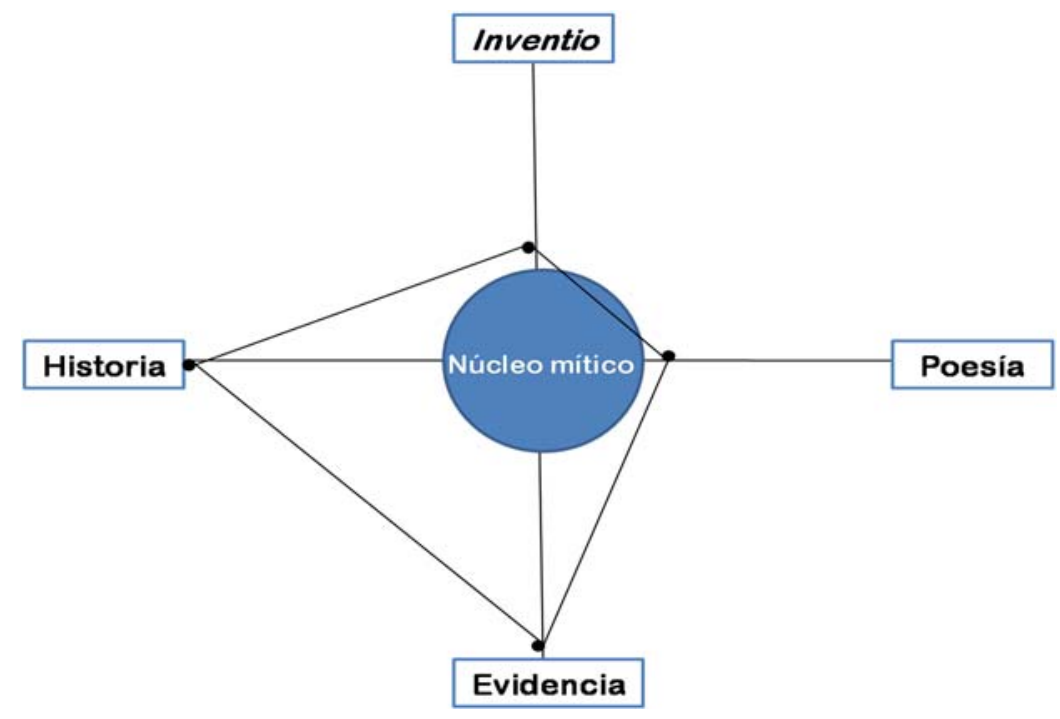


b) Seva, Luis López Nieves

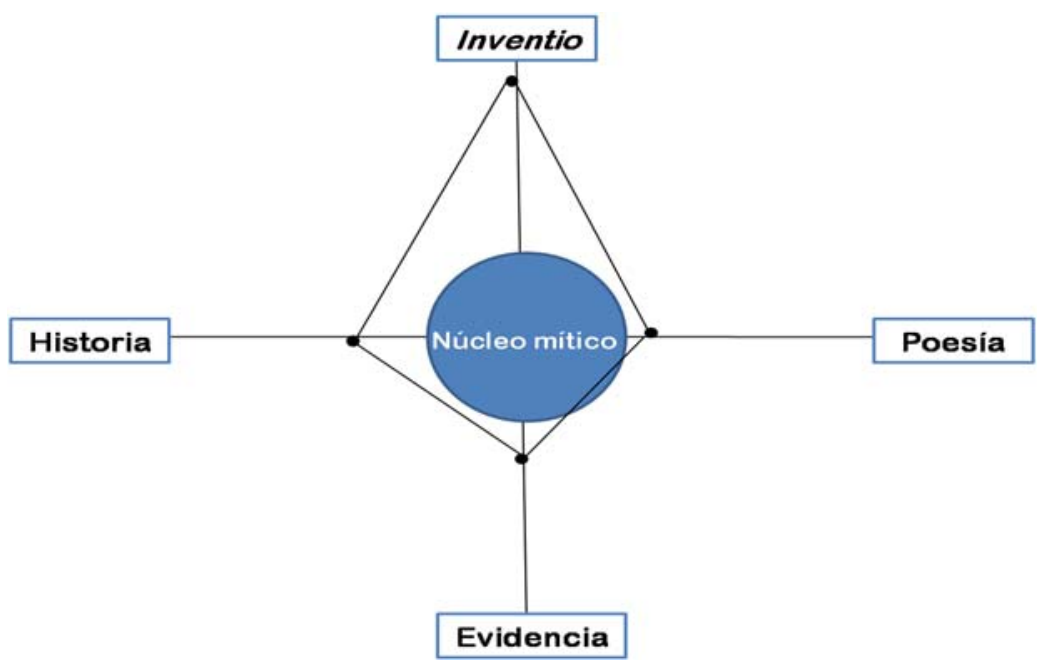

c) Nuevo Testamento

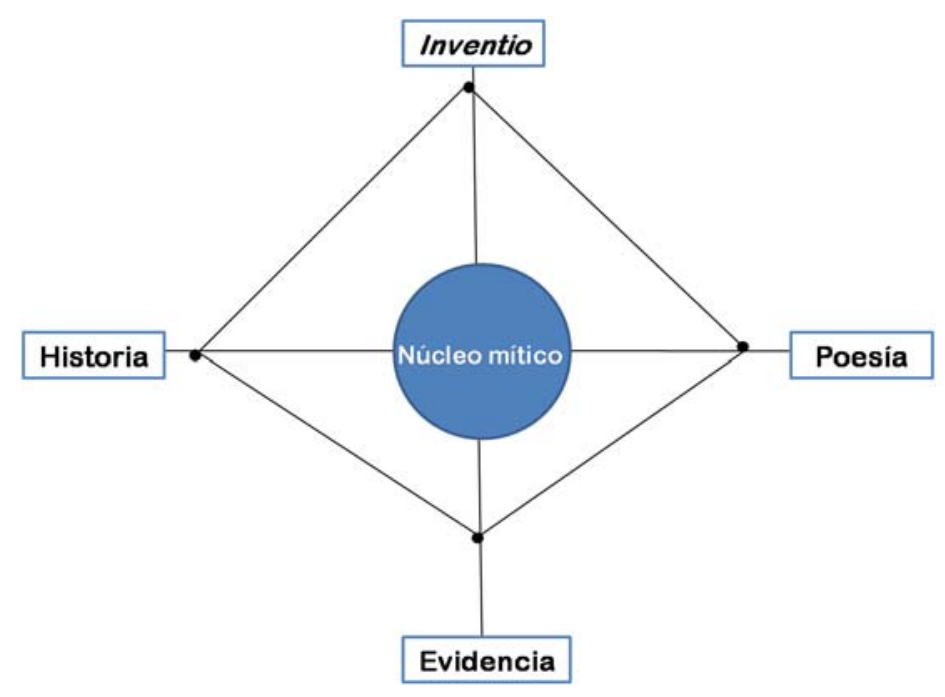

d) Veinte poemas de amor y una canción desesperada, Pablo Neruda

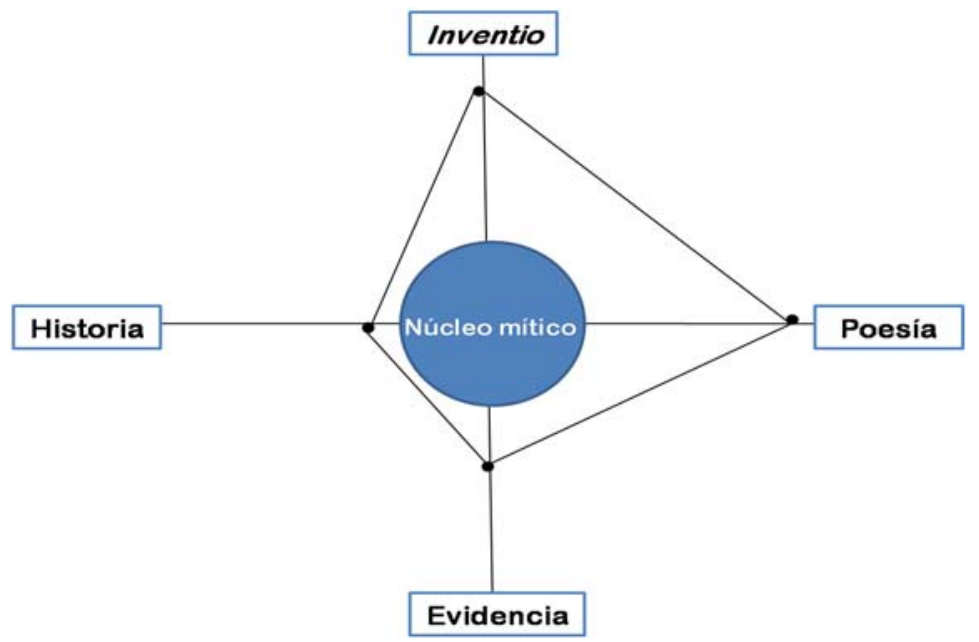




\section{Anexo II. Máquina ficcional de factura wittgensteiniana}

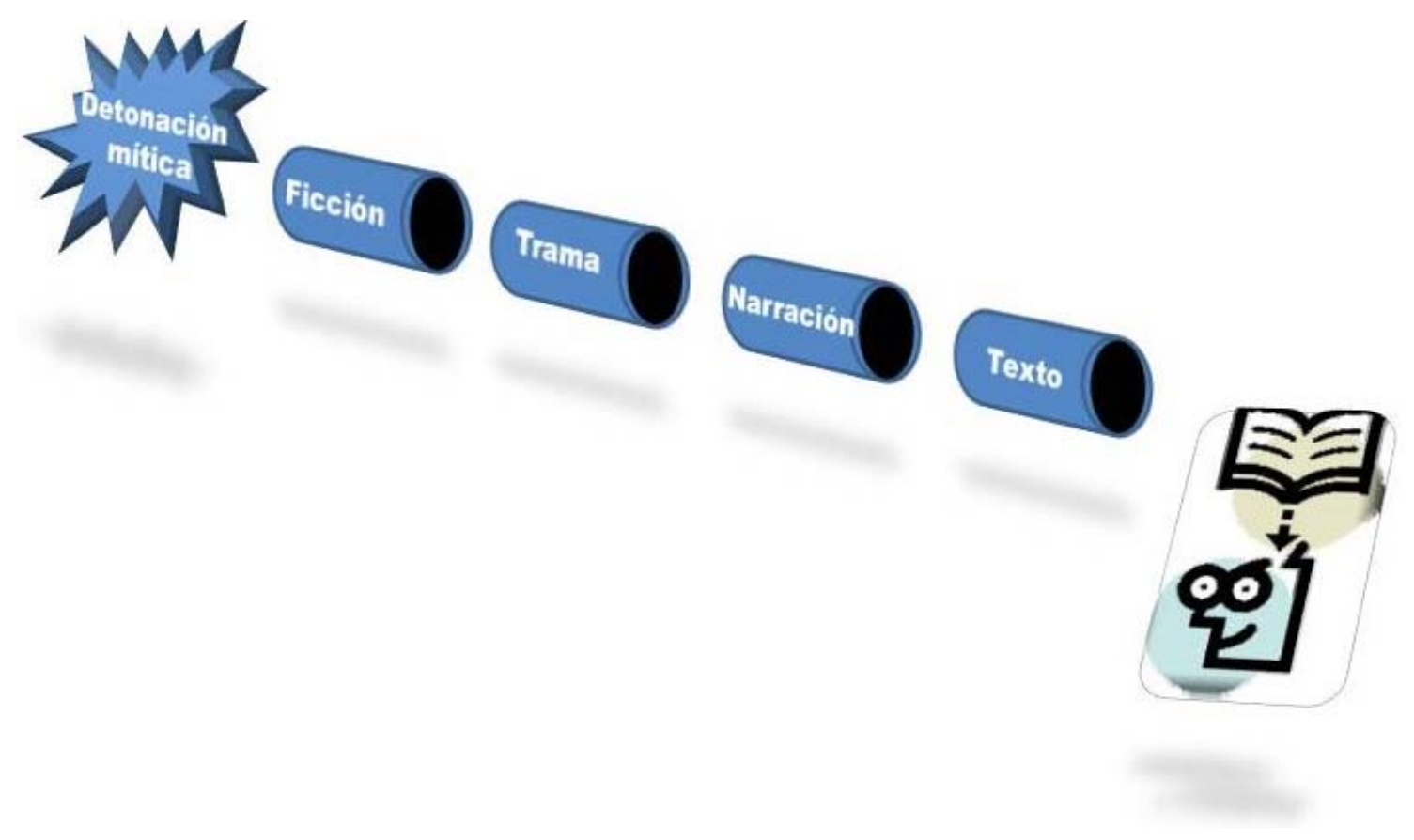

Este diseño maquínico asume dos premisas propuestas por Deleuze y Guattari en su obra El Anti Edipo: Capitalismo y esquizofrenia ${ }^{33}$, referidas a las máquinas:

1. "Una máquina se define como un sistema de cortes. [...] Toda máquina está en relación con un flujo material continuo (hylè) en el cual ella corta. [...] El corte no se opone a la continuidad, la condiciona, implica o define lo que corta como continuidad ideal" (2004: 42).

2. "Toda máquina es corte de flujo con respecto a aquélla a la que está conectada, pero ella misma es flujo o producción de flujo con respecto a la que se le conecta" (2004: 42)

La hylè que fluye por este sistema maquínico es el material mítico. El caudal fluye y se transforma en cada uno de los pasos de la ficcionalización: la ficción, la trama, la narración, el texto, la lectura (imagen 1). El material mítico, a la vez que se conserva en cada pieza, se contamina, se renueva, se actualiza. La factura wittgensteiniana radica en la transformación sufrida por el material mítico en cada entrada/salida, que es lo que impulsa el flujo.

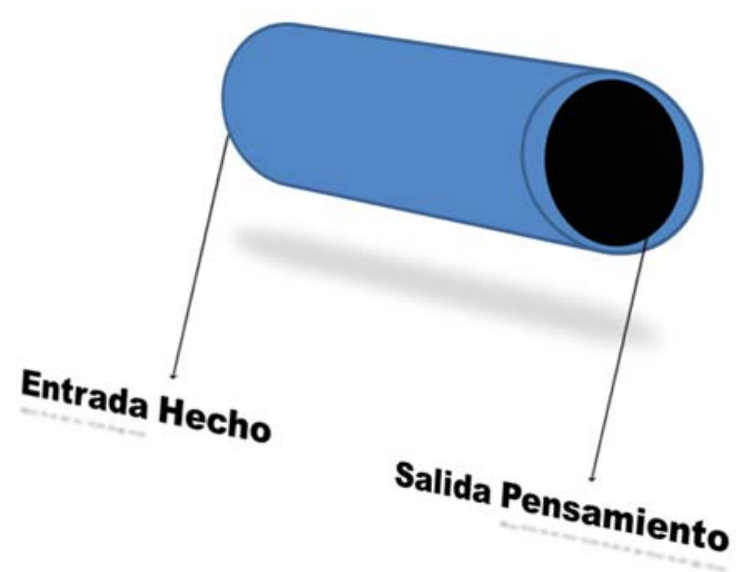


La entrada de cada pieza (primer corte) convierte a la hylè en Hecho/Tatsache ("la existencia de un estado de cosas"), pero la cuchilla de salida (segundo corte) la vuelve Pensamiento/Gedanke ("la representación lógica del hecho"). (imagen 2) O sea: la ficción es hecho en tanto la existencia de un estado de cosas, de relación estratégica entre los objetos de la Historia y de los objetos de la Poesía; pero pensamiento al racionalizar y representar en lenguaje y símbolos esa situación estratégica. El pensamiento de la ficción -su representación- engendra el hecho trama ficcional, las operaciones y procedimientos (teckné) que dan cuerpo al relato. La representación-pensamiento de la trama ficcional constituye el hecho narración, que es la adecuación temporal de esas "operaciones y procedimientos", la organización coherente de las acciones. La representación de la narración constituye el hecho texto literario, que se rige por normas estilísticas y estéticas. El hecho texto literario se vuelve representación en la lectura, cuando el sujeto se construye una imagen mental de lo que lee, una "representación lógica del texto". 